ERRATUM

Carl-Gustaf Thulin

\title{
Microsatellite investigation of roe deer (Capreolus capreolus) in Scandinavia reveals genetic differentiation of a Baltic Sea Island population
}

Published online: 17 August 2006

(C) Springer-Verlag 2006

In the abstract, the significance given for the differentiation between the population in Wittskövle and roe deer from Köpingsvik compared to all other populations should be " $p<0.01$," not $p<0.1$ as it reads now.

The online version of the original article can be found at: http://dx. doi.org/10.1007/s10344-006-0047-1.

C.-G. Thulin $(\bowtie)$

Population Biology and Conservation Biology,

Department of Ecology and Evolution, EBC,

Uppsala University,

Norbyvägen $18 \mathrm{D}$,

Uppsala, 752 36, Sweden

e-mail: carl-gustaf.thulin@ebc.uu.se

Tel.: +46-018-4716488

Fax: +46-018-4716424

C.-G. Thulin

Department of Animal Ecology,

Swedish University of Agricultural Sciences,

Umeå, 901 83, Sweden

C.-G. Thulin

Department of Animal Breeding and Genetics,

Swedish University of Agricultural Sciences,

Uppsala, 751 24, Sweden 